\title{
Los variados objetos de la antropología: una relación de sentidos desde La Araucanía, Chile ${ }^{1}$
}

\author{
Teresa Durán² \\ Marcelo Berhó ${ }^{3}$ \\ Noelia Carrasco ${ }^{4}$ \\ Héctor Mora ${ }^{5}$
}

Trabajo recepcionado: diciembre 2006

Trabajo aceptado: junio 2007

\section{RESUMEN}

El presente artículo gira en torno a la posibilidad de la antropología de estudiar las condiciones de su propia existencia (Hubinger, 1997). Según entendemos, esta posibilidad significa no solo hacerse las preguntas claves relativas a sus características en tanto ciencia social sino a su vez poder otorgarse respuestas operacionales que guíen el proceso de autoanálisis desde su praxis. Creemos que el contexto de La Araucanía de Chile ha proporcionado un clima psicosocial desafiante para explorar esta posibilidad, así como para configurar respuestas provisionales, que son las que en esta oportunidad deseamos explicitar, orientadas no solo hacia la sociedad nacional, sino también a la regional y la local. La Araucanía es una denominación metafórica que representa un espacio territorial, social y cultural diverso que incuba nichos de desigualdad socioeconómica, así como variabilidades socioculturales que refieren, por un lado, a una cultura "originaria" con una tradición ancestral y, por otro, a una sociedad nacional que se auto-comprende como moderna. Espacio en que existiría una memoria que puede reconstruir historias que otorgan vida a dicho territorio y, al mismo tiempo, desconoce la historia o la pierde de vista debido a la imposición compulsiva de tendencias contemporáneas postmodernas y/o reificantes del colonialismo. Para la antropología local, este ha sido el escenario propicio para el planteamiento reiterativo de preguntas tales como ¿qué estudiar?, ¿cómo estudiar?, ¿para qué estudiar? Asimismo, ha sido un campo en el cual hemos estado ensayando un diálogo a través de nuestras prácticas profesionales,

1 La base de este texto fue expuesta en el $52^{\circ}$ Congreso de Americanistas, celebrado en Sevilla, en julio de 2006.

2 Antropóloga, ex Directora del Centro de Estudios Socioculturales y docente de la Escuela de Antropología de la Universidad Católica de Temuco, Chile. cesc@uct.cl

3 Antropólogo, docente de la Escuela de Antropología de la Universidad Católica de Temuco, Chile. mberho@uct.cl

4 Antropóloga, Directora de la Escuela de Antropología de la Universidad Católica de Temuco, Chile. ncar@uct.cl

5 Antropólogo, docente de la Escuela de Antropología de la Universidad Católica de Temuco, Chile. hectmora@uct.cl 


\section{Revista CUHSO volumen $13 \div 01$}

incorporando la historia donde ella está ausente (Durán, 2002; Durán y Berho, 2003; Carrasco y Eyzaguirre, 2005; Durán, 2005).

El artículo especifica cada una de estas preguntas fundamentales desde el marco de la propuesta global que anida en el locus local y que aspira a ser contrarrestada y comentada por otras experiencias de renacimiento de la antropología en América Latina ${ }^{6}$.

PALABRAS CLAVE: Antropología, praxis, objeto, contexto

\section{ABSTRACT}

This article focuses on the possibility of anthropology to study the conditions of their own existence (HUBINGER, 1997). As we understand it, the abovementioned possibility means more than making the key questions relating to their characteristics as social science but to turn power granted operational responses to guide the process of self-analysis from its praxis. We believe that the context of the Araucanía, Chile, provides a climate of psychosocial challenging to explore this possibility and to set tentative answers, who on this occasion is directed not only toward the national society, but also to regional and the local.

Araucanía is a name that represents a metaphorical territory, with a socially and culturally diverse socio-economic and inequality incubated niches, as well as socio-cultural variability, on the one hand, to a culture "originated" with an ancestral tradition, to a national society that is self-understood as modern on the other. The space in which would be a memory that can reconstruct histories gives life to that territory and at the same time, unknown history or loses sight due to the imposition of compulsory postmodern contemporary trends of colonialism.

For the local anthropological community this has been the stage for the approach of repetitive questions such as what to study, how to study? Why would you study? It has been a field in which we have been rehearsing a dialogue through our professional practices, incorporating the story where it is absent (Durán, 2002; Durán and Berhó, 2003; Carrasco and Eyzaguirre, 2005; Durán, 2005).

The article specifies each of these fundamental questions from the framework of the overall proposal, nesting in the local locus and that aspires to be countered and commented on by other experiences of re-birth of anthropology in Latin America.

KEY WORDS: Anthropology - object- praxis - context

6 Por ejemplo, Escobar, P. (2000) “El lugar de la naturaleza y la naturaleza del lugar: globalización o postdesarrollo?". En La colonialidad del saber: eurocentrismo y ciencias sociales, perspectivas latinoamericanas. CLACSO. Buenos Aires. 


\section{Quién habla y objeto}

Los autores del presente artículo representan a un equipo de antropólogos en el que se intercalan dos unidades académicas de la Universidad Católica de Temuco: el Centro de Estudios Socioculturales (CES) y la Escuela de Antropología?.

El propósito de este artículo es compartir visiones sobre el objeto de la antropología asociadas a su construcción a partir de las prácticas profesionales, disciplinarias e interdisciplinarias en un horizonte de tres décadas. En este período, ha sido posible constituir una comunidad de opinión al alero de la cual han ido produciéndose una serie de trabajos antropológicos demostrativos de un proceso de crecimiento en complejidad que pretendemos sistematizar en esta oportunidad. Hipotéticamente concebimos que los objetos de la antropología estén asociados al desenvolvimiento del sentido de complejización con que va siendo asumido el quehacer antropológico en los contextos temporo-espaciales en que se lleva acabo. Tal crecimiento del sentido de complejidad concierne a la necesidad y posibilidad de superar la dualidad impuesta a la antropol ogía en tanto ciencia y en tanto humanidad. Solo mediante esta superación, esta disciplina puede revertir objetos depurados de connotaciones sociales y culturales, falsamente objetivos, para salir al encuentro de áreas de convergencia entre el debate de las ciencias sociales y las problemáticas inherentes de la vida social.

\section{Antecedentes}

Es posible describir el tipo de antropología chilena contemporánea como un quehacer que oscila entre una casuística temática predominante y un esfuerzo minoritario por otorgar sustento teórico actualizado al quehacer, que se caracteriza por una escasa práctica de la reflexividad como enfoque metodológico central. Se trata de una antropología que, no obstante -o quizá por lo mismo, aparece centralizada por las oportunidades que brinda la ciencia oficial nacional y que tiene cierta influencia en la sociedad, creando imágenes y referentes sociales que participan en la formulación de las políticas públicas y que orientan además a las subdisciplinas. Las tradiciones teóricas predominantes han sido las propias de la antropología funcionalista, específicamente culturalistas, en sus versiones clásicas y modernas.

En el marco de este panorama, nos parece conveniente situar la forma en que tanto el CES y la Escuela de Antropología, en el lapso de una década, se sitúa y vive el proceso de hacerse cargo de una tradición y transformarla. Precisamente en el $\mathrm{V}$ Congreso Chileno de Antropología, quienes representamos la tradición antropológica de Ios 70, mostramos cómo tal tradición había evolucionado en tres décadas:

- Desde un pensamiento que en este contexto se ha considerado clásico en la concepción profesional del desempeño y que, en lo disciplinario, es postestructuralista.

- Que se asocia al movimiento postclásico, en el sentido de que analiza la realidad social para participar en ella animando procesos emergentes de cambio social.

- $Y$ que se asume de carácter latinoamericanista en la perspectiva de la distinción e interrelación entre el rol profesional y disciplinario en el ámbito sociocultural del desempeño (Durán et al. 2005).

En realidad, los acercamientos enmarcados en esta perspectiva han sido variados en la forma y en el contenido y de ellos hemos dado cuenta en trabajos anteriores, particularmente en la edición № 207 de la

7 La primera entidad surge en 1997 y se reactualiza institucionalmente en el 2005, la segunda cuenta con una historia de retrocesos y avances desde 1971, época en la que se inserta en la política universitaria nacional, siendo hoy la unidad que, a nivel nacional, lidera los procesos de acreditación de carrera. 
Revista Anthropos titulada "Antropología y Sociedad. Una relación compleja, crítica y problemática". En este texto se demuestra el tránsito entre objetos-tipo-temáticas, circunscritos a su vez a una concepción teórica dada de la antropología, hacia la conformación de un enfoque antropológico que se propone llevar a cabo un quehacer en el cual los presupuestos teóricos de la disciplina se ponen a prueba respecto de su utilidad social e interpretativa a partir de problemáticas sociales explicitadas por sectores sociales identificables y que demandan el quehacer antropológico. Este enfoque se subsume en la denominada "Antropología Interactiva" en tanto fundamento teórico de una antropología aplicada contemporánea (Durán, 2002: 28). Enfoque que también fue revisado desde el punto de vista de la epistemología política (Carrasco y Eyzaguirre, op.cit.). ${ }^{8}$ Esta producción vislumbró un quehacer que hacía sentido con su base teórica fundante, adhiriendo al giro que las ciencias sociales y las ciencias en general venían anunciando desde los noventa (Gallopin, 2004).

Debemos advertir que el desempeño del rol ha venido complejizándose progresivamente toda vez que la antropología local protagonizó desafíos de representar una opinión socioética-política en el marco de escenarios institucionales gravitantes para el desempeño disciplinario y profesional: las instituciones sociales en las que ejerce o ha ejercido tal rol dual y también en las universidades como sistemas que producen y administran el conocimiento, conscientes o no del impacto que tal función tiene en las sociedades. Estas exigencias nos han estimulado a centrarnos en la vida cotidiana como contexto sine qua non desde donde se entrelazan las preguntas y las respuestas, sea sobre nosotros mismos como personas, sea como símiles del mundo social en el que estamos insertos y, de un modo más lejano, acerca de los fenómenos de diversa índole que determinan nuestro acontecer y el del mundo. En este ej ercicio configuramos el perfil del desempeño cotidiano del antropólogo, reconociendo los siguientes ámbitos:

- La esfera de la diferenciación social, determinantes en la incorporación y permanencia en los espacios institucionales, sean públicos 0 privados.

- La esfera que trasciende la diferencia social, cuando se conforman comunidades de opinión y no solo comunidades "científicas" y/o estamentos.

- Estados de angustia existencial en relación a la práctica etnográficoantropológica, que levanta problemáticas sociales, locales y globales, vinculadas al quehacer antropológico-científico.

En este ejercicio nos dimos cuenta que la concepción de antropología fundada en la vida cotidiana otorga la posibilidad de integrar el quehacer con la vivencia al Ilevarse a cabo desde la vivencia. Las vivencias no son únicamente personales, sino también sociales. Por tanto, pueden y requieren ser consideradas en el ejercicio cognoscitivo, ya que es el principal instrumento mediante el cual podemos conocer. Esto supone que las vivencias pueden ser direccionadas tanto para perfeccionar el conocimiento como para permitirle a la persona situarse en el mismo. De este modo, las vivencias cumplen dos funciones: permiten la construcción identitaria y dan pie a una revisión y autocrítica constante del proceso de construcción de conocimiento y sus resultados (Durán y Gutiérrez, 2005).

\section{Propuesta de antropología compleja desde la periferia}

La concepción de Pérez-Taylor (2002) de la antropología como una ciencia que

8 Fundada en una contrastación de las prácticas disciplinarias y profesionales de la antropología interactiva y la sistémica en Chile. 


\section{UNIVERSIDAD CATÓLICA DE TEMUCO}

estudia las formas de organización del género humano es lo suficientemente amplia como para incluir no solo la sociedad y cultura de la llamada 'otredad', sino también la sociedad y cultura del antropólogo. La concepción de este autor tiene la ventaja de relacionar el quehacer investigativo con "el fin de dar a conocer socialmente el estado de cosas en el que se encuentra la sociedad", I q que convierte al antropólogo en un actor crítico del mundo actual. Luego veremos sus limitantes en la praxis latinoamericana.

Como ya lo planteáramos, postulamos que los objetos de la antropología pueden reformularse en directa relación con los procesos de comprensión de los niveles de complejidad que impone el quehacer en las sociedades con las que el antropólogo se relaciona; en el caso latinoamericano, la propia-cercana y lejana o la ajena-cercana y lejana. En cierto sentido, esta concepción se condice con la definición de Herzfeld (1997) de antropología que focaliza el sentido común de las sociedades como el objeto principal de la disciplina, el que deberá abordarse desde una perspectiva comparativa. Ello para enfrentar la hegemonía conceptual y cosmológica del sentido común occidental.

En el cuadro siguiente graficamos esta concepción de antropología en la que se advierten varios objetos interrelacionados, a partir de la investigación etnográfica. Estos son de importancia relativa, pero fundamentales en el propósito de transitar hacia una imagen social que supere los riesgos que supone una antropología referida a objetos temáticos derivados solo del ejercicio investigativo clásico (Durán, 2005).

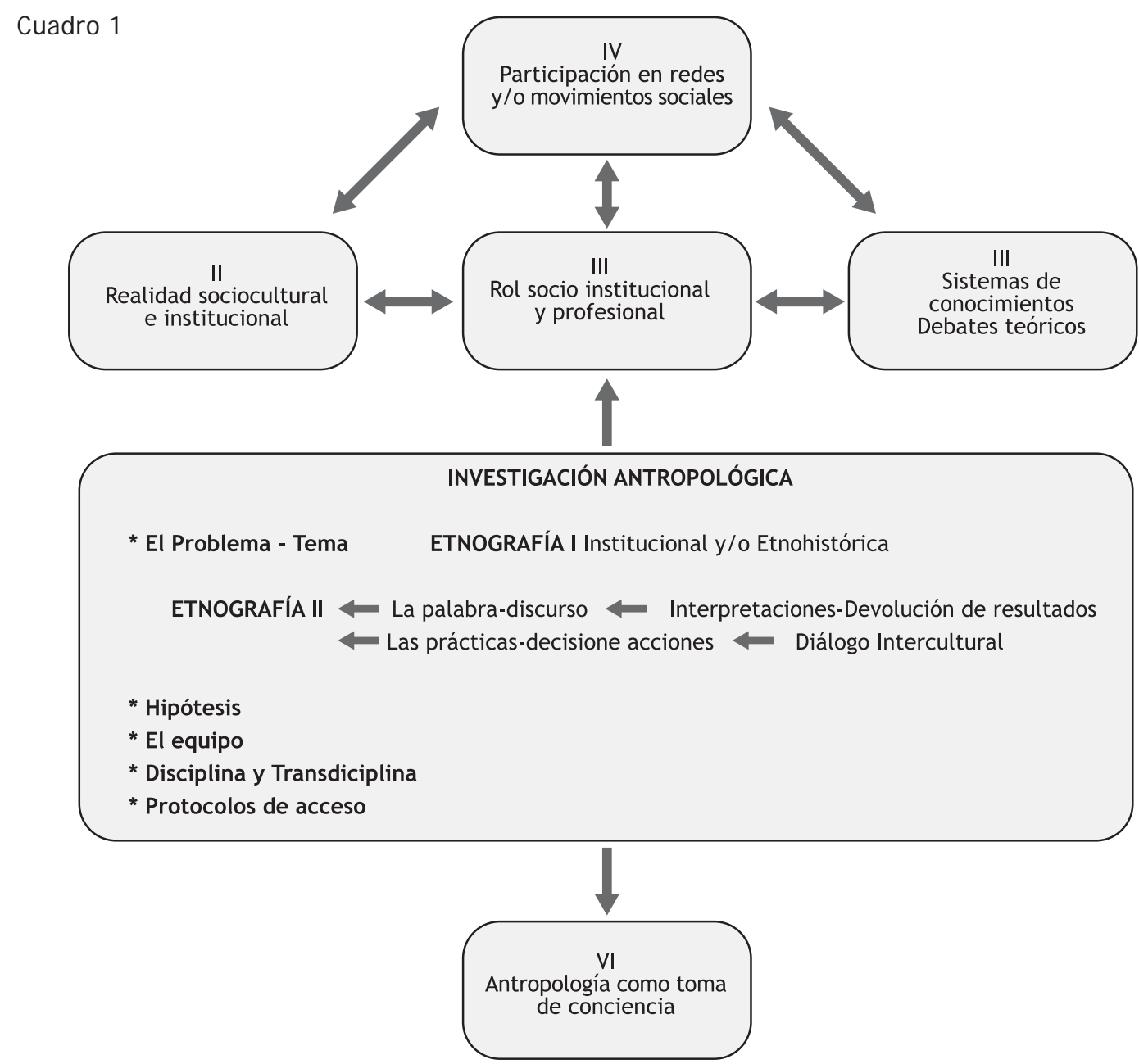


Acontinuación se reseñará brevemente el acontecer del desempeño en torno a dos principales y distintos objetos:

a) Ios derivados o centrados en el ejercicio de la investigación etnográfica-científica, y

b) los derivados del impacto de la sociedad global en el objeto cognoscitivo tradicional reformulado.

\section{Investigación antropológica}

En el cuadro expuesto, la investigación antropológico-etnográfica representa la base constitutiva de la disciplina, en el sentido en que esta alimenta el quehacer profesional y el disciplinario. De aquí la importancia que debemos asignarle a su forma y a su contenido.

En el contexto sociocultural de la Región de La Araucanía, han debido aplicarse los principios y las metodologías cualitativas de la Etnografía Clásica (I) y de la Etnografía Reflexiva (II). Esta última se refiere al hecho de reconocer que los protocolos científicos son también "etnométodos", es decir, prácticas derivadas de una visión particular de las cosas, propias del "mundo científico", que en cierto modo predeterminan los hallazgos de la investigación social. Una etnografía que busque ser lo más fiel posible a la naturaleza de su objeto de estudio debería dar cuenta simultáneamente del objeto de la investigación y del método utilizado durante la misma, a partir de la hipótesis de que ambos no solo están imbricados, sino que el conocimiento de uno facilita conocer al otro (Coulon, 1998; Hammersley y Atkinson, 1994). Estos autores permiten entender que la reflexividad es la capacidad de convertir las cosas, los temas, las situaciones, en objeto de análisis.

Por otro lado, en nuestra experiencia ha resultado útil, particularmente en estudios interdisciplinarios ${ }^{9}$, el uso de la denominada "teoría fundamentada" acuñada por Anselm Strauss y Juliet Corbin (2002). Esta, se sustenta en cuatro estrategias: 1) una indagación sistemática, a través de preguntas generativas, de las principales categorías sociales, que buscan establecer sus relaciones, 2) el muestreo teórico, 3) los procedimientos de categorización (codificación) sistemáticos, y 4) el seguimiento de algunos principios dirigidos a conseguir un desarrollo conceptual sólido (no solamente descriptivo). Para el logro de la última estrategia enunciada, los investigadores deben conceptualizar y diagramar una herramienta metodológica denominada "matriz condicional", la cual busca facilitar la especificación de las condiciones y consecuencias de la acción social, en una escala que va desde lo más macro hasta lo más micro, y que permite ir integrando los hallazgos a que conduce el uso de la teoría. Esta matriz, en palabras de los autores, puede visualizarse como "un conjunto de círculos, uno dentro del otro, cada nivel corresponde a diferentes aspectos del mundo [...] en los otros anillos se colocan aquellos rasgos condicionales más distantes a la acción o la interacción; mientras en los anillos más internos se sitúan aquellos rasgos catalogados más cercanos a la secuencia de acción o interacción". Cuando participamos en el proyecto interdisciplinario aprobado por la ciencia oficial, el uso de esta herramienta metodológica permitió diferenciar tipos de conocimientos identificando aquellos hitos diferenciadores de los mismos derivados de historias particulares así como de particularidades culturales: fue así como se distinguieron conocimientos ancestrales mapunche acerca del medio natural, conocimientos campesinos de raigambre nacionalista criollos, conocimientos científico-naturales postulados en el caso por la geografía física, conocimientos científicosociales en los que se ubica la antropología, disciplina que en el ámbito local postuló la posibilidad de la interrelación intencionada de tales conocimientos, propiciando espacios introductorios de "diálogo intercultural" de

9 Proyecto "Análisis integrado del borde costero", 2003-2006. 
modo de optimizar la pertinencia de procesos de planificación territorial ${ }^{10}$.

En efecto, en nuestras experiencias de investigación interdisciplinaria se han realizado dos tipos de análisis: el primero un análisis documental histórico-interpretativo y/o macroanálisis, orientado hacia una memoria de larga duración. Por otra parte, el microanálisis nutrido desde el análisis etnográfico del hacer/ decir social focalizándose en la acción local, generalmente en base a historias locales y concluyendo con el análisis de la configuración de los modos de vida, de las relaciones sociales, de los ceremoniales, del nivel organizativo en un plano más global.

Así, el trabajo de campo atraviesa genéricamente cuatro etapas. La primera corresponde a la obtención del acceso al escenario sociocultural en que se pretende estudiar; la segunda se orienta ala identificación y focalización del fenómeno o situación que abordará en el escenario sociocultural al que se ha accedido; la tercera se encamina a la definición o elección de los sujetos que participarán en el proceso de construcción de conocimientos, así como a la concreción de los modos de obtener la visión que estos tienen de la realidad objeto de estudio, de la cual ellos forman parte; la cuarta está referida al registro, ordenamiento, reducción, validación, análisis e interpretación de los datos recogidos. Es relevante aclarar que todas las etapas mencionadas, con excepción de la primera, se entremezclan dentro del proceso investigativo, dada la naturaleza recursiva de este.

Al inicio ya planteamos que en el contexto local interétnico se trabaja con sectores diferenciados social y culturalmente; y en este último caso contando con la participación de actores sociales interesados en los avances de la investigación. Es decir, las investigaciones antropológicas responden a una demanda social formalizada, dando lugar a un objeto antropológico en el que la interacción sujeto-objeto es constitutiva, incluyendo la direccionalidad del cambio.

Derivado de lo anterior, la investigación antropológica se ha vinculado de un modo cada vez más explícito con los niveles epistemológicos, así como con los factores que determinan el problema de investigación, es decir, con la dimensión sociológica y política. Ello, debido a la necesidad de visualizar, recursivamente, el plano filosófico y/o ideológico en la investigación, así como el social. Como plantea Bunge (2000:154-155), la investigación, sea básica o aplicada, es guiada por supuestos filosóficos y aun por una ideología, construcción cultural no científica, no necesariamente ajena a la ciencia; lo importante para él es que esta dimensión se sistematice o explicite, aserto que compartimos. El tema de las epistemologías es relevante, puesto que nos encontramos en una sociedad multicultural y de orientación interétnica e intercultural, es decir, en un ambiente social en el cual los grupos y/o actores sociales construyen códigos restringidos y/ o elaborados diversos y en movimiento, dependiendo de las circunstancias de la construcción. Por nuestra parte, hemos visto la necesidad de aumentar la conciencia acerca de la imposible neutralidad ideológica que pudiera sostener el plan de investigación, así como al mismo tiempo hemos debido esforzarnos para obtener resultados 0 "nuevas formas interpretativas de la realidad" que, por un lado, puedan ser útiles a los actores sociales para resolver sus problemas, especialmente cuando estos conciernen a cuestiones relacionadas con el conocimiento y, por otro, responden a debates teóricos identificables en la disciplina.

Cabe señalar aquí que los hechos a los que alude la fenoménica de la diversidad cultural generan dinámicas de desagregación que incluyen desde la formulación de etiquetas sociales identitarias, hasta prácticas sociales de reconocimiento y materialización de la diferencia. Este último ámbito corresponde

10 En la actualidad se prepara un artículo sobre construcción de conocimiento intercultural en torno a las categorías de agua (Durán, Catriquir y Peña). 
a un campo de asimetrías valorativas fundantes de nuestra razón práctica, que se expresan en la creación de conceptos como "país libre de racismo", "crisol de razas", "comunidad nacional", "identidad nacional", "blanqueamiento de razas", "chilenización", en fin, "indígena y no indígena", etc.

Asociada a estas creaciones culturales, vemos que los sujetos conforman necesariamente ciertos intereses materiales y simbólicos que, asumidos como propios, articulan reivindicaciones, Io que a su vez Ileva a manipular voluntaria o involuntariamente las adscripciones anteriores. Siguiendo en esta perspectiva debemos explicitar, entonces, que nuestro marco conceptual apunta a desentrañar la construcción social genérica de diferencias sociológicas denominadas étnico- culturales $\mathrm{y} / \mathrm{o}$ raciales $\mathrm{y}$, por otro lado, de un modo más profundo se enmarca en la consideración de que la explicitación del proceso de construcción del conocimiento puede constituirse en una herramienta eficaz para contribuir a ese desenmarañamiento, así como a proyectarlo a la vida social.

Por construcción del conocimiento vamos a comprender aquí el proceso y modo como los saberes humanos se estructuran, Io que implica no solo explicitar las condiciones que otorgan validez a las afirmaciones que sostenemos, sino también a la forma y contenido de estos conocimientos (Fourez, 2000)

Para este autor, los estudios epistemológicos han adquirido una dinámica que es necesario tomar en cuenta, distinguiendo tres grandes corrientes: la epistemología tradicional que trata de determinar las condiciones de nuestro conocimiento en el tiempo, preocupándose de preguntas relativas a la naturaleza de la verdad, la validez de los métodos y la pertinencia de las pruebas, el lugar del sujeto y el objeto en el conocimiento, el papel de la teorías, de la observación y de las explicaciones. Esta corriente es la que se expresa en el plan básico de toda investigación antropológica y que se presenta en el cuadro
$N^{\circ} 1$. Paralelamente se han desarrollado las epistemologías empíricas que examinan cómo construyen los seres humanos su conocimiento. En nuestro esquema esta epistemología la reconocemos en los marcos teóricos tales como el estudio del geosistema, desde el cual es posible evaluar el comportamiento humano según respuestas previsibles (Bertrand, 1978). En nuestro campo emerge de los actores sociales y particularmente de los especialistas que asumen marcos teóricos como herramientas de trabajo orientadas a construir interpretaciones directamente asociadas con tales marcos teóricos.

En el último tiempo se distingue la socioepistemología que estudia el conocimiento desde la dinámica social; y las epistemologías científicas que analizan lo que hacen los científicos en sus laboratorios. Siguiendo a este autor, mientras la primera de estas corrientes expresa de manera normativa cómo habría que pensar o razonar y la segunda cómo se procede de hecho, "la socioepistemología ve los desarrollos científicos como formados por la historia humana y se niega a situarlos en un universo aislado de los conocimientos" (Fourez, op. cit.: 19 - 21). Esta última corriente ha sido particularmente útil para los estudios interétnicos, y a ella correspondería, por ejemplo, la orientación que se le da a la etnografía reflexiva antes señalada y que permite focalizar las relaciones entre la ciencia clásica y las acciones humanas, así como la diferenciación entre tipos de conocimiento (ver nota 10).

En consideración al enfoque teórico que tematiza u objetiviza el proceso de construcción de conocimiento y considerando el contexto socioétnico, hemos utilizado operacionalmente la metodología de tránsito entre lo que Bernstein (Cit. en Ibíd. : 14) Ilamó "códigos restringidos" y "códigos elaborados". La distinción de estos códigos nos ha permitido distinguir distintos conocimientos dependiendo de las epistemologías que los fundamentan. Siguiendo a Bernstein, entendemos por código elaborado el que se inspira en la profundización de los hechos cotidianos y prácticos, con el 
afán de alcanzar capas más profundas de la vida en común o en relación. En La Araucanía, hemos tenido muchos ejemplos de este tipo de códigos; uno de ellos es la nominación de un nivel organizacional crítico en la Ley Indígena nacional y en la vida social; nos referimos al concepto de "comunidad" en el marco legislativo y al concepto ngen lof en calidad de código elaborado por parte del küpalme o familias mapuche demandantes de un proceso de recuperación territorial ${ }^{11}$.

El código restringido, por su parte, se concibe como representativo de quienes comparten los mismos presupuestos básicos sobre el tema del que hablan, afirmándose y/o autoafirmándose en relación a tales presupuestos. Al aplicar esta diferenciación operacional del conocimiento al contexto interétnico e intercultural en el que trabajamos, nos vemos obligados a nutrir este tránsito conceptual con la posibilidad de diferenciar estas elaboraciones respecto de referentes culturales diversos e intradiversos. En el caso anteriormente citado, por ejemplo, propusimos el concepto de "etnografía oficial" para referirnosal estudio que losfuncionarios de la Corporación Nacional de Desarrollo Indígena (CONADI) deben realizar, a partir de la "toma de razón" de la demanda de recuperación territorial y que fuera previamente introducida por el estudio etnográfico-académico ${ }^{12}$. En este caso, para el antropólogo funcionario la tarea etnográfica consiste en documentar los sitios de significación cultural definidos por la ley; en cambio, para el antropólogo investigador, este es el inicio para la construcción de una interpretación que se remite al pasado, al presente y a la visión de futuro de una situación desde la reflexividad étnico-cultural de los actores demandantes. Esta diferenciación del lenguaje y de los diversos posicionamientos ético-políticos de la investigación antropológica deriva en desempeños profesionales diversos y es la que ilustra el acercamiento interpretativo que estamos trabajando.

En efecto, dado que nuestros estudios consideran la incidencia de las políticas públicas y del conocimiento científico (natural y social) y tecnológico, la matriz analítico-contextual del conocimiento queda del siguiente modo:

\section{Cuadro $\mathbf{N}^{\circ}$ 2. Tipología de conocimientos interculturales desde una perspectiva etnográfica}

\begin{tabular}{|l|l|l|l|l|}
\hline \multirow{2}{*}{} & \multicolumn{2}{|c|}{ Código restringido } & \multicolumn{2}{c|}{ Código elaborado } \\
\cline { 2 - 5 } & No Mapunche & Mapunche & No Mapunche & Mapunche \\
\hline $\begin{array}{l}\text { Conocimiento } \\
\text { especializado }\end{array}$ & & & & \\
\hline $\begin{array}{l}\text { Conocimiento } \\
\text { común }\end{array}$ & & & & \\
\hline $\begin{array}{l}\text { Conocimiento } \\
\text { tecnológico }\end{array}$ & & & & \\
\hline
\end{tabular}

Asumimos que esta matriz analítica es de carácter dinámico y recursivo, y sintetiza un proceso de sistematización en torno a la construcción de conocimiento, la cual puede permitir, como se deriva de su nomenclatura, interpretar el material empírico que proviene de las expresiones discursivas de los diferentes actores sociales (construcciones culturales y legislativo-institucionales) respecto de los ámbitos priorizados por las investigaciones. Lo que interesa señalar aquí es que, al complejizar el tema de los objetos de la antropología nos vemos enfrentados al desafío de captar el dinamismo sociocultural en el que se ven

11 Objeto de estudio hoy en curso y que nos sitúa en el proceso de creación de conceptos en contextos de conflictividad social. Peña).

12 "El sitio Portawe Lelfün, comuna de Galvarino, IX Región. Fundamentos para el reconocimiento del patrimonio cultural mapuche", documento elaborado por el antropólogo Marcelo Berho, 2006. 
envueltos los actores sociales con quienes negociamos el ej ercicio del rol profesional. En esta perspectiva, si ellos enfrentan problemas estructurales y situacionales, asumimos que el quehacer antropológico debe también abordarlos, mediante un acercamiento de procesos en el que confluyan disciplinas diferentes, consensuando una metodología multidimensional, a fin de analizar e interpretar el presente mediante comparaciones interculturales e intraculturales, al mismo tiempo que a través de la confrontación de estas respecto de cuerpos interpretativos y/ o normativos de políticas sociales y/ o de teorías sociales disponibles (Durán y Berhó, 2004).

Una metodología así concebida para el ámbito de los estudios mapuche tiene importancia teórica y ética, dado que concierne no solo a la(s) imagen(es) de las sociedades o grupos que el especialista construye, sino también al comportamiento estratégico de los actores involucrados en el contexto del estudio. En este punto, la reflexividad construida hasta aquí indica que la metodología usada es clave. Este problema se ilustra con el hallazgo de que la última imagen especializada construida sobre la sociedad mapuche ha sido la que proporcionó el enfoque estructuralorganizacional en los años setenta (Stuchlik, 1976). Como se sabe, esta imagen introduce la necesidad de separar el nivel estructural del social y al mismo tiempo establecer su debida interrelación en situaciones específicas. Aunque en principio el enfoque teórico se conserva hasta el presente, la metodología que hoy se ha operacionalizado es diferente, por la consideración de la variable interrelación con la sociedad nacional, que explícitamente no fue considerada en el estudio etnográfico. Por otra parte, aunque la etnografía que hoy protagonizamos, de igual modo comparte la corriente postclásica reflexiva e introduce una variedad relevante, dado que se establece sobre la base de variables previamente elegidas por los equipos y actores sociales, ha desplazado y reemplazado la permanencia prolongada en los contextos de estudio, como correspondía al método convencional, por estudios progresivos y enlazados entre sí con estrategias metodológicas complementarias en torno a los procesos sociales. Lo anterior nos lleva a pensar que las imágenes que se construyen de las sociedades dominadas, como el caso de la sociedad mapuche, hasta el momento han sido mayormente de responsabilidad del antropólogo o de los funcionarios u otros sociales y, en nuestra perspectiva, del impacto derivado de las políticas públicas, faltando por construirse una imagen en la que los actores sociales tengan cada vez injerencia y responsabilidad más evidente.

En el campo de la marginalidad social extrema, referido al estudio de las personas sin hogar, los llamados moradores de la calle ( Márquez, F., 2008 en prensa), en tanto, el esfuerzo ha consistido en una articulación progresiva de esquemas teóricometodológicos socio-antropológicos dentro de una práctica que, orientada reflexivamente, ha avanzado desde una posición monológica autoclausurante del objeto y la posición del investigador, hacia otra que incorpora, por una parte, el principio de la doble hermenéutica que hace posible repensar la investigación antropológica como una construcción históricosocial y no como un fin en sí mismo, externo a toda motivación que no sea la del sujeto cognoscente $y$, por otra parte, que asume la complejidad y/o multidimensionalidad de la realidad social a medida que las delimitaciones iniciales del objeto van ampliando el espacio a través del análisis relacional del sujeto marginal y el no marginal de las que el propio antropólogo se hace parte, en principio como lego y posteriormente como actor social relativamente competente-.

La operacionalización de estos principios implica llevar a cabo una interacción intencionada de parte del antropólogo hacia y/ o con diversos actores sociales, marginales y no marginales, teniendo que asumir virtuales consecuencias no esperadas ni deseadas. Asimismo, obliga a emprender un tipo de tratamiento autorreflexivo de las propias construcciones teórico-metodológicas del objeto y de los modos de interacción desde el ámbito de la ciencia y la sociedad de origen. 
De este modo, se asume una perspectiva de conocimiento que recoge y explora permanentemente nuevos antecedentes que son transformados y canalizados en nuevos procesos de negociación y práctica del conocimiento antropológico de orientación interactiva (Berhó, 2005).

\section{Realidad sociocultural e institucional}

Como se ha dado a entender aquí, el trabajo disciplinario y profesional que corresponde llevar a cabo se inserta en una sociedad autodenominada moderna, que cuenta con un ideario teórico-político-constitucional que se reproduce mediante una democracia representativa animada por partidos políticos de sectores sociales polarizados (derecha e izquierda) de larga data y en la que se manifiestan movimientos sociales de incidencia relativa, centrados minoritariamente en cuestiones estructurales y mayormente en temáticas emergentes (derechos de las minorías, crisis económicas, educacionales, corrupción público-administrativa, etc.). En lo económico y sociopolítico el país presenta indicadores que lo ubican en un proceso decidido de integración a la economía global, en el cual el Estado ha cumplido un rol facilitador. Derivado de ello, el polo de integración tecno-económica periférica trae consigo una acentuación de las diferencias entre ricos y pobres. Las políticas indígenas, en tanto, emulan pobremente los avances teóricos en relación al desarrollo sostenible, al desechar el conocimiento cultural y la acción social propia de los miembros de la sociedad indígena, tanto en la forma como en la ej ecución de las políticas (Caniullan, 2005). A nivel institucional, la antropología no está incluida como disciplina constitutiva de los estamentos profesionales, siendo el ámbito más inmediato del desempeño, el universitario. No obstante, un sector importante de antropólogos ejercen su carrera en las instituciones públicas y privadas. Este es un hecho relevante a la hora de diferenciar y eventualmente interrelacionar Ios códigos elaborados y/ o restringidos respecto del conocimiento institucional o tecnológico, ámbito que genera controversias dignas de exploración etnográfica y sociológica. Tanto la marginalidad urbana como las relaciones interétnicas e interculturales conforman cuerpos institucionalizados y administrativos de concepciones, normas y preceptos que orientan la relación social y cultural; no obstante, el tránsito entre los hallazgos de las ciencias sociales y su institucionalización es precario. Esta dimensión está siendo especialmente considerada en nuestro estudio de las prácticas profesionales ${ }^{13}$.

III. Los sistemas de conocimiento y los debates teóricos

Actualmente las exigencias sociopolíticas depositadas en el rol han ido aumentando. La participación de la antropología local en la formulación del plan estratégico de la Universidad en el marco del proceso de auto-acreditación y de la tendencia orientada al mejoramiento de la calidad de la educación superior, ha significado la oportunidad de incorporar la perspectiva antropológica en temas antes ajenos a la disciplina; particularmente lo que concierne a la relación entre ciencias naturales y ciencias sociales, cuestión que impacta directamente en los procesos de generación de conocimiento y en los respectivos ordenamientos socioculturales y éticos, especialmente en el campo de las relaciones interétnicas. La consideración de la perspectiva antropológica en el ámbito de la distribución del conocimiento a nivel institucional está ofreciendo oportunidades no consideradas con anterioridad para el cuerpo institucional, lo que en el marco de nuestra interpretación nos obliga a reconocer en ello un nuevo "objeto de la antropología local". En efecto, se ha debido impulsar un proceso de revisión del quehacer científicoinstitucionalizado respecto de la situación pasada, presente y futura que vive el pueblo mapuche en nuestra región. Al respecto, y analizando el quehacer institucional, nos preguntamos:

13 Este estudio se inicia el 2003 y se mantiene vigente al 2007. 
- ¿A partir de qué modelo de investigación científica se abordan los estudios sobre los pueblos originarios, en este caso sobre el pueblo mapuche? ¿Incluyen estos modelos la participación de esta población en los procesos de génesis, desarrollo y canalización del conocimiento hacia la sociedad regional y nacional?

- ¿Existe preocupación institucional por los posibles impactos que la investigación científica (natural y social) tiene en la población originaria y en las políticas que la afectan?

Al establecer este nuevo objeto de preocupación de la antropología local, reflexionamos en la perspectiva que plantea Carrithers (2005) cuando se pregunta qué debe decir o hacer la antropología frente a un evento mundial de tanto impacto como la declaración de guerra de Estados Unidos a Irak, tras lo cual se preguntó si la antropología sociocultural podía ofrecer una base para la crítica moral y social, respondiéndose que el sentido de posibilidad representaría la habilidad para pensar lo que podrían ser las cosas, sin otorgarle a las cosas más importancia que la que tienen. Esta reflexión nos parece que es fundamental en nuestro ámbito local para hacernos cargo de la relación entre el quehacer universitario y la realidad del pueblo mapuche. Al respecto planteamos la siguiente hipótesis operacional: La relación entre el conocimiento especializado, la organización de su proceso de construcción y los movimientos sociales de apoyo a la sobrevivencia digna de los pueblos indígenas, es azarosa y, en tanto tal, desfavorable a este propósito sociocultural.

Esta hipótesis se trabajó con antecedentes institucionales en el horizonte de los dos últimos años en relación al siguiente problema de conocimiento: ¿Qué vinculación con movimientos sociales presentan los proyectos de investigación oficialmente registrados en la Universidad y de parte de qué unidades académicas?

Los resultados del examen de los datos revelan que en la Universidad Católica de Temuco, la historia del pueblo mapuche, así como las características socioeconómicas y socioculturales de su población, constituyen aún temáticas de disciplinas particulares y/o antecedentes de proyectos sociales más que fundamentos de políticas institucionales explícitas de vinculación con el medio regional. Ello obedecería, por un lado, a una cuestión socio-cultural general de desconocimiento y desinterés de parte de la sociedad nacional y regional respecto del componente indígena del país $y$, por otro, a la escasa legitimidad que este tipo de estudios tiene en el marco del modelo de ciencia oficial. Solo en forma excepcional se ha podido "intervenir" este estilo de ciencia mediante acercamientos etnográficos reflexivos y participativos hacia la búsqueda de articulaciones con sentido entre tipos de conocimiento. Desde el año 2005 la Universidad Católica de Temuco adoptó un discurso institucional que integra la preocupación por el impacto regional de la investigación científicotecnológica. Del mismo modo, insertó la necesidad de desarrollar investigación interdisciplinaria y aplicada, dirigida hacia el tratamiento de problemas sociales específicos. Este discurso, si bien resulta compatible y próximo al estilo de investigación social que la antropología promueve desde la perspectiva de la reflexividad, parece contradecir o dificultar el imperativo de la productividad científica basada en el supuesto según el cual "a mayor productividad internacional, mayor impacto del conocimiento a nivel regional y local".

Entretanto, la perspectiva de profundización epistemológica, que busca una aproximación ética y política más acorde con los indicadores de sobrevivencia ${ }^{14}$ de los pueblos indígenas en las sociedades nacionales

14 Según lo indican los estudios lingüísticos recientes (Zúñiga, 2006), sólo el 16\%de la población mapuche es hablante de mapudungun, la lengua originaria. El impacto de la castellanización ha sido estudiado desde los '90 y se ha abordado parcialmente a través de las políticas públicas -Academia de la Lengua y programas ElB-. 
sigue en avance mediante la elaboración de programas de comunicación enmarcados en la tendencia postulada por los especialistas del conocimiento, denominada "diálogo de saberes" (Ghiso, 2000). A nivel local interesa de modo particular establecer vinculaciones entre el conocimiento cultural (mapunche-kimün) y el científico natural y social, acometiendo trabajos etnográficos que ayuden a visualizar "el significado profundo y trascendente de los patrimonios culturales mapunche para la vida, la identidad y el destino de un pueblo, una región, y por cierto un país" (Berhó, 2006: 2).

Lo anterior sería indicativo de que la antropología local está transitando desde el estudio de temáticas específicas hacia el debate sobre los modelos de ciencia a partir de la incorporación de criterios de objetivación del quehacer que toman en cuenta las variables socioculturales provistas por el contexto, para insertarse así en un proceso de cambio de las ciencias sociales, requerido desde los estándares éticos que conforman el sustrato institucional de la disciplina (Grupo de Barbados, 1991). Este estilo de antropología se corresponde con la llamada "antropología interactiva" que señalábamos al inicio de este artículo (Durán, 2002, op. cit.) y que hoy entendemos como el acercamiento teóricometodológico de orientación aplicada que permite diseñar un programa de participación antropológica en el conocimiento y tratamiento de problemáticas sociales mediante un proceso etnográfico reflexivo en el que concurren, procedente de la lógica especializada, las dimensiones socio-estructural, microsocial u organizativa y subjetiva, buscando la pertinencia social del diálogo a través del uso de códigos de comunicación inter-sociales y/o inter-culturales propios del contexto donde se lleva a cabo dicho quehacer, utilizando los conocimientos especializados construidos sobre la problemática y sobre el tipo de comunicación a través de la cual se la aborda.
Esta concepción de la antropología aplicada asume que cada actor tiene una parte de la responsabilidad social en el proceso de construcción de conocimiento, sea en la etapa previa al diseño científico, en su formulación, en su ejecución y/o en su impacto, prevaleciendo la labor evaluativa del mismo a fin de reorientarlo y consumarlo en orden al cumplimiento de los objetivos definidos o redefinidos, conocidos por los sectores involucrados.

Otro campo que se debe considerar en este ámbito es el que se refiere a la interdisciplina. Un miembro del equipo ha reflexionado en torno a las posibilidades que la formación metodológica tiene en el campo interdisciplinario. Se plantea que las condiciones que propician la interdisciplina no están dadas de antemano, por lo que es necesario que estas se desarrollen en la formación académico-profesional de pregrado. De este modo, se propone generar una apertura hacia una "pedagogía de la investigación científica", donde la comprensión metodológica posibilite la comunicación y el diálogo entre las disciplinas (Mora, H., 2005).

\section{Participación en redes sociales}

Enel marco delaspolíticasuniversitarias vigentes ya indicadas, la comunidad de opinión participa también en redes regionales que dinamizan la preocupación por explicitar y activar los principios democráticos, particularmente los de la participación social, en relación con las distintas problemáticas que la sociedad regional presenta. En esta perspectiva, la antropología interactiva permite coordinar acciones con sentido e impulsar el conocimiento especializado en el mundo social al mismo tiempo que nutrirse de la experiencia de instituciones sociales de larga trayectoria ${ }^{15}$.

En esta perspectiva, la comunidad de opinión debe abrirse a las concepciones

15 En 2006 el CES y la Escuela de Antropología participaron en la organización del primer Foro Social de La Araucanía, cuya temática central fue el análisis de la realidad del pueblo mapuche en la sociedad regional y nacional. 
y prácticas de las instituciones sociales y fundamentalmente entender los diseños de sociedad que emergen de aquellas instituciones que explícitamente abordan la diferenciación social con fines de reparación y/o de superación. Este enfoque se articula con lo planteado por Herzfeld (op. cit.), quien sostiene que cada vez es menos "defendible la separación entre la esfera intelectual y la política". En contextos socioculturales como los señalados, la antropología puede constituir un recurso valiosísimo al agregar sustantividad al conocimiento social, por ejemplo, sobre las problemáticas interétnicas y, al decir de Herzfeld, "porque sus técnicas características de 'desfamiliarización' pueden utilizarse para cuestionar los supuestos universalizantes que predominan cada vez más en la adopción de decisiones políticas" (op. cit.) Se visualiza en este contexto, pues, otro ámbito de desempeño en el marco de la definición de un objeto antropológico, esta vez de impacto sociocultural.

\section{Rol socio-institucional y profesional}

La relación establecida entre el conocimiento antropológico y el social fue planteada por la vía de la diferenciación de roles antropológicos y su articulación teóricometodológica (Durán y Berhó, op. cit.). Hoy día esta relación está siendo sistematizada sobre la base de los antecedentes que arrojan las prácticas profesionales en las instituciones locales en la que los estudiantes de antropología se desempeñan. Por lo tanto, ha resultado una línea de trabajo fecunda que, en el marco de la antropología interactiva, intenta resolver la dicotomía teoría-práctica y en definitiva "desempeño disciplinario/ desempeño profesional". En el plano teórico, se plantea el siguiente problema: cómo trasladar apropiadamente el debate que particulariza a las ciencias sociales contemporáneas hacia el abordaje profesional situado. En el campo de las relaciones interétnicas e interculturales y sintetizando el análisis naturalista de autores contemporáneos en una muestra azarosa ${ }^{16}$ en relación al enfoque teórico, encontramos que estos conforman una diáspora que va desde una interpretación de los hechos sociales, facilitada desde un acercamiento metodológico y/ o disciplinario explícito, a una interpretación de carácter tipológico intermediada por un constructo teórico que cubre varios niveles de realidad, pudiendo desembocar en propuestas de salida al tema. La problemática pendiente va en la dirección de establecer de qué modo esta diáspora puede facilitar y/ o enriquecer el desempeño profesional.

En el campo de la marginalidad social extrema, el rol profesional ha sido desempeñado a partir de la vinculación del antropólogo con el mundo socio-institucional que asiste a la población de personas sin hogar en la ciudad de Temuco. En este contexto, el rol se ha diferenciado de modo crítico de los roles funcionales sostenidos sobre la base de modelos culturales caritativos de cariz religioso, así como de los asistenciales más o menos profesionalizados. En cualquiera de los casos, la negociación del acceso y mantención dentro del contexto ha requerido una fuerte conjunción de las competencias propiamente disciplinarias del rol antropológico y el desarrollo de una conciencia socio-ética abierta al diálogo y la confrontación interinstitucional. Este proceso no ha estado exento de aprensiones, celos y otras actitudes que obstaculizan o rivalizan con el potencial especializado del desempeño antropológico en la sociedad, a pesar de la confluencia en los fines que en principio motiva acciones de colaboración. Con todo, nuestra práctica del rol sugiere la necesidad de potenciar las capacidades y aptitudes de agenciamiento institucional y personal en función de desarrollar discursos y prácticas que superen, por un lado, la inercia asistencial y, por otro, avancen hacia mayores niveles de integración social. Para ello hemos desplegado acciones "pedagógicas" orientadas a visibilizar el problema del sin hogarismo como un problema

16 Artículos compilados en Samaniego, M. y Garbarini, C.G. (Comps.) (2004), Rostros y fronteras de la identidad. Pehuén, Universidad Católica de Temuco. Santiago. 
social complejo al interior de nuestras sociedades y a reconocer y despejar el cuerpo de conocimientos sociales estereotipantes y estigmatizantes dominantes que pueden cristalizar ya sea en los propios discursos institucionales 0 bien en el de sus agentes. ${ }^{17}$ En este marco descubrimos que, una vez que se han reconocido dichos estereotipos y estigmas por parte de quienes los usan, es posible fundar nuevos conceptos y prácticas de relación que reconduzcan procesos de marginación hacia la articulación de condiciones de vida menos asimétricas.

\section{Antropología como toma de conciencia}

De todo lo anterior se deriva que la investigación etnográfica postnormal (Funtowicz y Ravetz, 1999) conduce a la antropología desde un escenario metodológico acotado, a objetos de estudios "de segundo orden" y de orientación sociológica. En este sentido, la antropología como disciplina y profesión se transforma en una oportunidad de toma de conciencia sobre la forma de organización del género humano en contextos en los que intervienen componentes socioculturales propios de la sociedad a la cual pertenece el antropólogo y de sociedades que por razones históricas responden a una pertenencia forzada a esta.

\section{Sistematización de la antropología compleja}

En consideración a la importancia que el contexto ha tenido en la evolución de la antropología regional (Durán et al., 2005, op. cit.) y considerando la influencia de los factores sociales, culturales y políticos en el quehacer que constituye a su objeto, así como las formas en que este ha intentado responder creativamente a dicho contexto, hemos elaborado las siguientes hipótesis de salida a ser abordadas en el marco disciplinario:
1. El objeto del quehacer antropológico reflexivo puede ser interpretado y analizado por sujetos con distintas aproximaciones al quehacer.

2. El objeto del quehacer antropológico puede enunciarse como parte fundamental de un quehacer sociocultural.

3. El quehacer del antropólogo puede redireccionar su propia determinación a partir del ejercicio de hacer consciente tal producción y de intencionar la reformulación de su objeto.

Estas hipótesis representan el desafío al que la antropología local se enfrenta ante complejidades a las que tiene acceso progresivo en relación a la ampliación de su foco de interés inicial y la visualización de sus posibilidades de acción. Asumimos que en el contexto de La Araucanía la disciplina se enfrenta con tales posibilidades en la medida que recoge, intentando trascender, los componentes multidimensionales del problema etnográfico, definiendo responsabilidades de diferente contenido entre ambos planos. En otras palabras, el contexto le exige al antropólogo y, al mismo tiempo, le permite no solo "pedir una explicación" (Carrithers, op. cit.) sobre los hechos sociales y políticos, sino también delimitar áreas de investigación y acción en cada uno de ellos, con lo cual también auto-delimita el ámbito de su ineludible responsabilidad social.

\section{BIBLIOGRAFÍA}

BERHÓ, M. (2005), "Antropología de la marginalidad extrema. Una propuesta local". En Revista Anthropos, № 207: 43 - 53.

BERHÓ, M. (2006), “El sitio Portawe Lelfün, comuna de Galvarino, IX Región. Fundamentos para el reconocimiento del patrimonio cultural mapuche". Informe final, Escuela de Antropología, Universidad Católica de Temuco, Chile.

17 Cabe señalar que este esfuerzo incluye también la propia producción del antropólogo, especialmente cuando este expone sus hallazgos frente a sus pares. De este modo, la práctica de la desfamiliarización de las narrativas dominantes se vuelca sobre la propia praxis antropológica con el fin de evitar y/ o reducir eventuales sesgos sociales. 
BERTRAND, G. (1978), “Le paisaje entre la nature et la sociéte". En Revue de Geographie et du Sudouest, Tome 49F: 239-258.

BUNGE, M. (2000), Epistemología. Siglo XXI Editores. México.

CARRASCO, N. y EYZAGUIRRE, L. (2005), “La antropología vista por la epistemología política. Comentarios a la antropología aplicada chilena". En Revista Anthropos, № 207: 185-200.

CARRITHERS, M. (2005), "Anthropology as a Moral Science of Possibilities". En Current Anthropology 46 (3): 433 - 456.

COULON, A. (1998), La etnometodología. Cátedra, Colección Teorema. Madrid.

DURÁN, T. (2002), “Antropología interactiva: un estilo de antropología aplicada en la IX Región de La Araucanía. Chile". En Revista CUSHO VI (1): 23 - 57.

DURÁN, T. y BERHÓ M. (2003), "Antropología interactiva: conciencia y práctica dual del rol del antropólogo en una sociedad multiétnica y multicultural". En Revista CUSHO VII (1):

DURÁN, T. y BERHÓ, M. (2004), “Modelos y prácticas de la interculturalidad. Bases fundantes". En SAMANIEGO, M. y GARBARINI, C.G. (Comps.), Rostros y fronteras de la identidad. Pehuén, Universidad Católica de Temuco. Santiago.

DURÁN, T. y GUTIÉRREZ, L. (2005), “El quehacer de la antropología en la vida cotidiana". En Revista LIDER 14 (10): 105-120.

DURÁN, T. (2005), “Duplicando la antropología desde La Araucanía, Chile". En Revista Anthropos, № 207: 23 - 42.

DURÁN, T., CARRASCO, N. y BERHÓ, M. (2005), "Reflexividad y contexto en el quehacer antropológico". En Revista CUSHO IX (1): 9-25.
DURÁN, T., CATRIQUIR, D. y HERNÁNDEZ, A. (2007), Patrimonio cultural mapunche. 3 Volúmenes. Universidad Católica de Temuco, Consejo Nacional del Libro y la Lectura, Gobierno de Chile. Santiago.

FOUREZ, G. (2000), La construcción del conocimiento científico. Sociología y ética de la ciencia. Ediciones Narcea S.A. Madrid, España.

FUNTOWICZ, S. y RAVETZ, J. (1999), "PostNormal Science - an Insight Now Maturing". En Futures 31 (7): 641-646.

GALLOPIN, G. (2004), "Sostenibilidad y desarrollo sostenible. Un enfoque sistémico". En Serie Medio ambiente y Desarrollo, № 64 . Series CEPAL. Santiago.

GHISO, A. (2000), "Potenciando la diversidad. Diálogo de saberes, una práctica hermenéutica colectiva". Disponible en http: / / bibliotecadigital. conevyt.org. $m x$ / colecciones/documentos/ potenciando_ diversidad.pdf

HAMMERSLEY, P. y ATKINSON, M. (1994), Etnografía. Métodos de investigación. Paidós. Barcelona.

HERZFELD, M. (1997), “Perspectivas Antropológicas: Perturbar las estructuras del poder y el conocimiento". En Revista Internacional de Ciencias Sociales № 153, UNESCO. Disponible en http://www.unesco. org/ issj / rics153/ herzfeldspa. html

HUBINGER, V. (1997), "Antropología y modernidad". En Revista Internacional de Ciencias Sociales, $N^{\circ} 154$, UNESCO. Disponible en http:// www. unesco.org/ issj/ rics154/ hubingerspa.html

MORA, H. (2008), “La formación metodológica como posibilidad de interdisciplina: hacia una pedagogía de la investigación científica". (En prensa en Revista Chilena de Integración de Psicología, para publicación Vol. $1 \mathrm{~N}^{\circ} 1$, diciembre 2008). 


\section{UNIVERSIDAD CATÓLICA DE TEMUCO}

PÉREZ-TAYLOR, R. (2002), Antropología y complejidad. Gedisa, Barcelona.

SAMANIEGO, M. y GARBARINI, C.G. (Comps.) (2004), Rostros y fronteras de la identidad. Pehuén, Universidad Católica de Temuco. Santiago.

STRAUSS, A. y CORBIN, J. (2002), Bases de la investigación cualitativa: técnicas y procedimientos para desarrollar la teoría fundamentada. Editorial Universidad de Antioquia. Medellín, Colombia.

STUCHLIK, M. (1976), Life on a Half Share. C. Hurst \& Co. Publishers Ltd. London.

ZUÑIGA, F. (2006), Mapudungun. El habla mapuche. Centro de Estudios Públicos, Andros Impresores. Santiago, Chile. 